\title{
Thermal infrared imaging for the detection of relatively warm lacustrine groundwater discharge at the surface of freshwater bodies
}

Amaya I. Marruedo Arricibita, Stephen J. Dugdale, Stefan Krause, David M. Hannah, Jörg Lewandowski (1) https://orcid.org/0000-0001-5278-129X

DOI

10.1016/i.jhydrol.2018.05.004

Original publication date

4 May 2018 (Available online)

Document version

Accepted manuscript

Published in

Journal of Hydrology

\section{Citation}

Marruedo-Arricibita AI, Dugdale SJ, Krause S, Hannah DM, Lewandowski J. Thermal infrared imaging for the detection of relatively warm lacustrine groundwater discharge at the surface of freshwater bodies. Journal of Hydrology. 2018;562:281-9. 


\section{Accepted Manuscript}

Research papers

Thermal infrared imaging for the detection of relatively warm lacustrine groundwater discharge at the surface of freshwater bodies

Amaya I. Marruedo Arricibita, Stephen J. Dugdale, Stefan Krause, David M.

Hannah, Jörg Lewandowski

PII:

S0022-1694(18)30330-5

DOI: https://doi.org/10.1016/j.jhydrol.2018.05.004

Reference:

HYDROL 22781

To appear in:

Journal of Hydrology

Received Date: $\quad 24$ October 2017

Revised Date: $\quad 29$ April 2018

Accepted Date: $\quad 3$ May 2018

Please cite this article as: Marruedo Arricibita, A.I., Dugdale, S.J., Krause, S., Hannah, D.M., Lewandowski, J., Thermal infrared imaging for the detection of relatively warm lacustrine groundwater discharge at the surface of freshwater bodies, Journal of Hydrology (2018), doi: https://doi.org/10.1016/j.jhydrol.2018.05.004

This is a PDF file of an unedited manuscript that has been accepted for publication. As a service to our customers we are providing this early version of the manuscript. The manuscript will undergo copyediting, typesetting, and review of the resulting proof before it is published in its final form. Please note that during the production process errors may be discovered which could affect the content, and all legal disclaimers that apply to the journal pertain. 
Thermal infrared imaging for the detection of relatively warm lacustrine groundwater discharge at the surface of freshwater bodies

Amaya I. Marruedo Arricibita $a, b$, Stephen J. Dugdale, Stefan Krause , David M. Hannah $_{c}$ and Jörg Lewandowski

a Department of Ecohydrology, Leibniz-Institute of Freshwater Ecology and Inland Fisheries, 12587 Berlin, Germany.

b Department of Geography, Humboldt University of Berlin, 10099 Berlin, Germany.

cSchool of Geography, Earth and Environmental Sciences, University of Birmingham, B15 2TT

Birmingham, United Kingdom.

Corresponding author: Amaya I. Marruedo Arricibita

(marruedo@igb-berlin.de) 


\section{Abstract}

Thermal infrared (TIR) imaging has been previously applied to survey relatively large thermal footprints in coastal zones, lakes, reservoirs and rivers. In freshwater systems, the buoyancy of relatively warm groundwater during the winter months allows for the surface identification of groundwater discharge or thermal pollution using TIR imaging. However, information regarding the performance of TIR for resolving this warm groundwater upwelling is limited, particularly at fine spatial scales and variable discharge rates. In order to evaluate the suitability of TIR to trace warm groundwater upwelling at the water surface of lakes, ponds and reservoirs (e.g. lacustrine groundwater discharge (LGD) in shallow near-shore zones) we conducted a mesocosm experiment with a TIR camera situated $4 \mathrm{~m}$ above the water surface to capture thermal patterns in response to different groundwater discharge rates, weather conditions and the diurnal cycle. A fiber optic distributed temperature sensing system (FO-DTS) installed at $2 \mathrm{~cm}$ below the water surface was used to ground-truth spatial patterns observed in TIR images. Results show the impacts of both the diurnal cycle of net radiation and prevailing weather conditions on the accuracy of TIR imaging for resolving warm groundwater discharge. Most reliable results were obtained under overcast weather conditions and during the night. The results of our study provide guidance for those looking to use TIR for conducting thermal tracing of LGD at the surface of freshwater bodies during winter.

\section{Keywords}

TIR, FO-DTS, groundwater, lake, heat tracing, leakage 


\section{Introduction}

The use of thermal infrared (TIR) remote sensing is increasingly popular in the earth and environmental sciences for mapping of temperature patterns and thermal anomalies in water bodies (Dugdale, 2016). As such, TIR imaging has been applied in a wide range of contexts for monitoring of naturally occurring natural processes such as submarine groundwater discharge (SGD) in coastal areas (Johnson et al., 2008; Lee et al., 2016; Tamborski et al., 2015), groundwater discharge in streams and lakes (Hare et al., 2015; Wawrzyniak et al., 2016), volcanic activity (Davies et al., 2008) or hydrothermal systems (Neale et al., 2016). It is also used for the identification of anthropogenic impacts on hydrological systems including thermal effluent from power plants (Wang et al., 2016) and surface water contamination by illegal sewers or storm drainage (Lega and Napoli, 2010).

TIR imaging allows for the measurement of water surface temperature at high spatial resolution across a wide range of scales (Dugdale, 2016). While TIR has been relatively under-used until recently (in comparison to other remote sensing techniques), the increasing affordability of TIR has led to a recent uptake of this technology. This increased use of TIR has driven a range of literature reviewing the technological applications and limitations of satellite, airborne and ground-based TIR remote sensing (e.g. Dugdale, 2016; Handcock et al., 2012; Mundy et al., 2016; Sobrino et al., 2016) for the monitoring and mapping of water temperature anomalies in both marine and freshwater environments.

In marine systems, Submarine Groundwater Discharge (SGD) is a major source of nutrients and other chemical components (Burnett et al., 2006, 2003; Danielescu and MacQuarrie, 2011; Johnson et al., 2008; Taniguchi et al., 2002). SGD is known to affect water quality and 
phytoplankton dynamics, potentially leading to environmental phenomena such as eutrophication and algal blooms (Anderson et al., 2002; Hu et al., 2006; Lee and Kim, 2007).

In freshwater systems, groundwater discharge can create discrete temperature anomalies that serve as thermal refugia for fish and other ectothermic species (Baker et al., 2014; Brabrand et al., 2002; Hayashi and Rosenberry, 2002; Warren et al., 2005). Groundwater discharge can also impact nutrient budgets of lentic ecosystems (Boulton et al., 1998; Meinikmann et al., 2013; Shaw et al., 1990) and may play a role as a potential vector for pollution in streams and lakes (Nakayama and Watanabe, 2008).

Due to the importance of groundwater discharge in marine and freshwater systems, the literature abounds with TIR remote sensing-based methods for the detection of diffuse and discrete groundwater discharge. In marine systems, Johnson et al. (2008) demonstrated that TIR imagery is an appropriate tool for mapping SGD. More recently, Tamborski et al. (2015) combined airborne TIR with radium $\left({ }^{223,224} \mathrm{Ra}\right)$ and radon $\left({ }^{222} \mathrm{Rn}\right)$ surface water sample collection to quantify diffuse SGD. Similarly, Lee et al. (2016) demonstrated how combining aerial TIR imagery with field observations can be used to identify large groundwater inputs from coastal aquifers to the ocean. In freshwater environments, Schuetz and Weiler (2011) used ground based TIR thermography to detect discrete groundwater discharge into streams. A similar experiment by Briggs et al., (2016) demonstrated how ground-based TIR can reveal fine scale groundwater discharge patterns which would have not been resolved by other (coarser) methodologies. At larger scales, Wawrzyniak et al. (2016) used airborne TIR to resolve cold water patches in a riverine system as a function of the temperature difference between the river (in low flow conditions) and groundwater inputs. 
Groundwater detection using TIR is more straightforward in marine than freshwater environments due to the large density difference between groundwater inflow and the saline water column. Unlike in marine environments, where these salinity differences drive SGD upwelling, groundwater upwelling in freshwater systems is largely driven by temperature. Even small temperature differences may provoke groundwater-surface water density gradients that approach levels of buoyancy similar to that of groundwater discharge in saline systems (Lewandowski et al., 2013). This buoyancy, amongst other factors, enables the detection of groundwater upwelling at the surface of freshwater bodies. However, because the groundwatersurface water temperature difference can vary substantially, the ability of TIR to resolve groundwater upwelling is less consistent than in marine systems. While many publications (eg. Briggs et al., 2016, 2013; Danielescu et al., 2009; Dugdale et al., 2015; Tcherepanov et al., 2005; Wawrzyniak et al., 2016) document the use of TIR to detect groundwater upwelling in freshwater bodies, the vast majority of these studies focus on the detection of cool thermal anomalies in summer, with relatively little attention paid to the quantification of warm groundwater-surface water exchanges in winter. Furthermore, the examples that do exist which describe TIR imaging to detect winter groundwater upwelling in freshwater environments focus on groundwater discharge: (i) in streams (eg. Hare et al., 2015; Wirth et al., 2012); (ii) at marine beaches (Röper et al., 2014) and; (iii) in vernal and peatland pools (Frisbee et al., 2016), rather than in lentic waterbodies where mixing patterns are substantially different.

In addition, while previous studies (e.g. Briggs et al., 2016; Dugdale et al., 2015; Hare et al., 2015; Schuetz et al., 2012; Schuetz and Weiler, 2011) highlight the reasonable ability of TIR remote sensing to detect thermal anomalies related to groundwater discharge in real world freshwater environments, there remains a lack of formal 'laboratory-style' data evaluating the 
precise hydrological (e.g. discharge rates) and meteorological (e.g. weather conditions) conditions under which TIR remote sensing best detects groundwater upwelling, especially during the winter season.

In light of this these knowledge gaps, we present the results of a mesocosm experiment designed to test the suitability of TIR for tracing the upwelling of discrete lacustrine groundwater discharge (LGD) in lentic waterbodies (e.g. in shallow near-shore zones of lakes, ponds and small reservoirs). Our specific objectives were: (i) to compare (both visually and quantitatively) TIR observations of surface water temperature with simultaneously-collected FO-DTS temperature data measured $2 \mathrm{~cm}$ below the water surface and (ii) to evaluate the suitability of ground-based TIR for the detection of spatial patterns in relatively warm groundwater upwelling as a function of different discharge rates, weather conditions and the diurnal cycle.

\section{Methods}

\subsection{Experimental design}

The mesocosm used in this study contained two inlets and one outlet (Figure 1). Water from Lake Müggelsee located in Berlin, Germany (mean of $4.7^{\circ} \mathrm{C}$ over the course of the experiment) was injected into the corner of the mesocosm via one of the inlets (rate $\approx 33 \mathrm{~L} \mathrm{~min}^{-1}$ ). The inlet remained open at all times to keep water temperatures well-mixed and relatively constant. The other inlet was installed at the base of the mesocosm and used for controlled warm water injections. A hosepipe was connected to this inlet to provide warm water. The pipe was insulated with foam to reduce cooling along the flow path from the tap to the mesocosm (approximately 65 m). Temperature of the injected flow (measured at halfway between the tap and mesocosm) 
ranged from 14 to $16{ }^{\circ} \mathrm{C}$. A nozzle was connected to the end of the inlet and covered with sediment to realistically simulate dispersal of the injected water through a layer of sediment. Finally, an outlet at the other side of the mesocosm was used to maintain a constant water level of $0.82 \mathrm{~m}$. Discharge at this outlet varied from 34 to $48 \mathrm{~L} \mathrm{~min}^{-1}$ depending on the warm water injection rate (Marruedo Arricibita et al., 2018).

<Figure 1 here, please>

Figure 1. Schematic of the mesocosm's experimental design including TIR setup and the upper layer of the FO-DTS.

For the FO-DTS surveys, an aluminium frame of dimensions $4 \mathrm{~m}$ x $2 \mathrm{~m}$ x $1.5 \mathrm{~m}$ (Figure 1) was installed within the mesocosm. The aluminium frame was used to support the FO cable in a gridlike pattern $2 \mathrm{~cm}$ below the water surface (Figure 1). The FO cable grid consisted of 15 lines (rows) of cable spaced $12.5 \mathrm{~cm}$ apart. An ULTIMA-S DTS (SILIXA Ltd.) instrument with a sampling resolution of $12.5 \mathrm{~cm}$ was used for the FO-DTS surveys. This experimental setup essentially resulted in gridded temperature measurements with a resolution of $12.5 \mathrm{~cm}$. Temperatures were acquired with a temporal frequency of 10 seconds (mean of the preceding 10 second period; essentially the integration time of the FO-DTS). $500 \mathrm{~m}$ of $2.8 \mathrm{~mm}$ diameter Corning ClearCurve simplex fiber (loose tube, 1 multimode fibre, both ends terminated with E2000/APC connectors) were deployed for the experiments. This selected FO cable specification allowed bending and was thus appropriate for installation in the aluminium frame (Marruedo Arricibita et al., 2018). 
Thermal images were acquired from a TIR camera installed $4 \mathrm{~m}$ above the mesocosm on a steel frame (Figure 1) and oriented perpendicular to the water surface. The FO-DTS measurements were used for ground truthing of the TIR results which only capture direct surface temperatures (ie. the upper $10 \mu \mathrm{m}$ of the water surface ;Torgersen et al., 2001). We used a VarioCAM® hr head camera (InfraTec GmbH) with 640 x 480 pixels $(7.5-14 \mu \mathrm{m})$. The camera was equipped with a wide angle lens with focal length of $12.5 \mathrm{~mm}$ and field of view (FOV) $65^{\circ} \times 51^{\circ}$. The temperature measurement range is -40 to $1200{ }^{\circ} \mathrm{C}$ and reported measurement accuracy is $\pm 2{ }^{\circ} \mathrm{C}$ or $\pm 2 \%$.

\subsection{Measurement protocol and calibration}

\subsubsection{FO-DTS}

Calibration of the FO-DTS was carried out using reference sections of fibre optic cable immersed within ice baths containing a mix of ice and water (maintained at $\sim 0.2{ }^{\circ} \mathrm{C}$ ). The first and last $20 \mathrm{~m}$ of fibre optic cable were submerged in this well mixed ice bath, and an external temperature probe connected to the DTS device used to monitor calibration bath temperatures independently. For differential loss corrections, fixed value settings were chosen along the relatively short cable $(500 \mathrm{~m})$ without any splices (Marruedo Arricibita et al., 2018). A default value of $0.255 \mathrm{~dB} / \mathrm{km}$ was used. This is the expected value for Corning ClearCurve OM3 fibre. A two-way single-ended measurement setup was deployed with alternating bidirectional monitoring of the light pulse sent from the DTS device (Krause and Blume, 2013). 


\subsubsection{TIR}

The TIR camera used in this study has an uncooled microbolometer FPA detector (uncooled Focal Plane Array) with an internal shutter. Small alterations in the microbolometer manufacturing process lead to non-homogeneous pixel specific sensor parameters which can induce temperature non-uniformities in the image (Tempelhahn et al., 2016, 2015). The camera's non-uniformity correction system (NUC) compensates for these minor sources of error by using an internal optical shutter that periodically covers the whole camera field of view to provide a reference temperature. In this manner, the TIR camera performed a NUC (also known as a Flat Field Correction) every 90 seconds to correct for temperature or thermal drift effects on the measurements (eg. Chen et al., 2011; Dugdale, 2016; Handcock et al., 2012; Tempelhahn et al., 2015, 2016).

A simple MATLAB function was developed to compensate for the effects of vignetting which created a minor systematic radial temperature gradient in the raw TIR images. This was achieved by applying a convolution filter with a smoothing window of 25 pixels to the raw imagery and subsequently creating a new image whereby each pixel is assigned a value equal to the difference between its smoothed value and the mean of all pixels within the image. The resulting raster essentially contained an inverse image of the vignetting effect which was then subtracted from the raw TIR image resulting in a final corrected TIR image.

Since the aim of the present study is to evaluate the suitability of TIR to determine spatial patterns of warm water upwelling, rather than quantifying rates of upwelling per se, absolute temperatures were not of specific interest and were not calculated for the data obtained by the TIR camera. Instead, we compared the TIR-derived data to the FO-DTS observations by 
computing the difference in minimum temperature $(\Delta \mathrm{Tmin})$ observed by the (corrected) TIR image and the FO-DTS device.

\subsection{Study period and influence of discharge rates, weather conditions and diurnal cycle}

Six 24-hour temperature datasets of simultaneously-acquired FO-DTS and TIR data were used in the present study (Table 1). The temperature datasets were obtained during 11 to 27 March 2015. In order to assess the performance of the TIR methodology at different discharge rates and weather conditions, injection rates were varied between 1,5 and $15 \mathrm{~L} \mathrm{~min}^{-1}$ under a range of different (ie overcast and clear) sky conditions. Overcast vs. clear weather conditions were inferred from data acquired from a weather station installed alongside the mesocosm, whereby relative solar radiation was defined as the ratio of observed shortwave radiation (measured by the weather station pyranometer) to the computed maximum solar radiation that would be expected using clear sky conditions (after Allan et al., 1998). For example, average relative shortwave radiation measured on 26 March 2015 of 0.17 was considered 'overcast' whereas the value on 19 March 2015 of 0.97 was classified as clear. Performance of the TIR methodology was examined at different points throughout the diurnal cycle to evaluate differences between day and night conditions.

Table 1. 24-hour measurements with FO-DTS and TIR camera. The control dataset is only used as a reference for the initial conditions of the mesocosm measurements and is not included in the results.

\begin{tabular}{lll}
\hline Injection rate $\left(\mathrm{L}\right.$ min $\left.^{-1}\right)$ & Weather conditions & Date (in March 2015) \\
\hline $\mathbf{0}$ (control) & overcast & 11 \\
$\mathbf{1}$ & clear & 19 \\
\hline
\end{tabular}




\begin{tabular}{lll}
\hline $\mathbf{1}$ & overcast & 26 \\
$\mathbf{5}$ & clear & 18 \\
$\mathbf{5}$ & overcast & 27 \\
$\mathbf{1 5}$ & overcast & 12 \\
\hline
\end{tabular}

\subsection{Comparison of TIR temperature data with FO-DTS temperature data}

We assessed the performance of the TIR data for locating and measuring the spatial extent of warm groundwater upwelling by comparing the TIR data with FO-DTS. Because the TIR images essentially contain multiple 'layers' of radiation resulting from solar radiation and/or longwave reflections (from trees, clouds, etc), it is necessary to determine the extent to which the temperature signal from the warm water discharge matches that recorded by the FO-DTS data, in light of these other sources of noise. This was accomplished both visually and quantitatively.

\subsubsection{Visual comparison}

A direct comparison of the FO-DTS and TIR thermal image data was difficult, given the different spatial resolutions of both methods and the fact that FO-DTS provided a spatially integrated temperature along a 2-dimensional cable section while TIR produced gridded temperature data. To enable comparison between the TIR and FO-DTS data, the portion of the TIR image corresponding to the extent of the FO-DTS measurements was extracted from the TIR images of the mesocosm. The TIR images were then down sampled to the same resolution of the FO-DTS temperature data matrix, allowing the resulting 30x15 pixel TIR matrices to be compared to the FO-DTS grid.

We visually compared the average temperature grids generated by the FO-DTS and TIR approaches for the first 3.5 minutes of each hour. Although the FO-DTS temperature data showed clearer spatial temperature patterns when averaged over longer periods of time, this was 
not the case for the temperature data monitored by the TIR camera, presumably due to increased surface movement in comparison to the FO-DTS (submerged at $2 \mathrm{~cm}$ below the surface). Indeed, averaging the TIR temperature data over long periods of time resulted in overly blurred or smoothed patterns. Therefore, the decision to focus on the $3.5 \mathrm{~min}$ period represented a compromise between the two methods.

Temperature anomalies caused by external factors such as leaves, branches or ducks on the water surface were identified and masked out before plotting the resulting temperature grids for the FO-DTS and TIR data. Temperature values found to be outside of 3 standard deviations above or below the mean were considered outliers due to external factors and were also removed.

\subsubsection{Quantitative comparison}

In addition to visually comparing the TIR and FO-DTS temperature grids, we quantified spatial correlation between the TIR and FO-DTS grids generated in section 2.3.1 using Bivariate Global Moran's I. Bivariate Global Moran's I is essentially a global measure of spatial association between two different variables in corresponding neighbourhoods. In this case Bivariate Global Moran's I can thus be understood as an average value representing the correlation between the entire TIR and FO-DTS grids (eg. Anselin, 1995; Anselin et al., 2002). 


\section{Results}

\subsection{Comparison of TIR temperature data with FO-DTS temperature data}

\subsubsection{Visual comparison}

To highlight differences resulting from variations in injection rate, time of day and technique employed (FO-DTS and TIR), we visually compared pairs of FO-DTS and TIR temperature images with the lowest (ie. worst) and highest (ie. best) spatial correlation (based on Bivariate Global Moran's I coefficients; see Figures 2 and 3) under overcast (Figure 2) and clear sky (Figure 3) weather conditions for injection rates of $1 \mathrm{~L} \mathrm{~min}^{-1}, 5 \mathrm{~L} \mathrm{~min}^{-1}$ (Figure 2 and 3) and $15 \mathrm{~L}$ $\min ^{-1}$ (Figure 2). The figures show the averages of $\Delta$ Tmin for the first 3.5 minutes of each hour.

\section{Overcast conditions}

Under overcast conditions with a $1 \mathrm{~L} \mathrm{~min}^{-1}$ warm water injection rate, the lowest spatial correlation occurred at 20:00 in the evening (Figure 2.a). The FO-DTS data showed warmest temperatures on the right side of the image resulting from the injected warm water at the bottom of the mesocosm. Conversely, the TIR data showed warmest temperatures on the left side of the image. This is likely due to the fact that images recorded at this low discharge rate were dominated by thermal reflections of a tree overhanging the left side of the mesocosm, which obscured the temperature signal corresponding to the warm water injection (indicated with a black arrow in Figure 2.a, TIR image). In contrast, the best spatial correlation between the FODTS and TIR temperature at a $1 \mathrm{~L} \mathrm{~min}^{-1}$ injection rate occurred at 02:00 in the morning (Figure 2.a), whereby there was a strong visual overlap between warmest areas in the FO-DTS and TIR data. 
Under a $5 \mathrm{~L} \mathrm{~min}^{-1}$ injection rate, the worst spatial correlation occurred at 07:00 in the morning (Figure 2.b). Similar to the $1 \mathrm{~L} \mathrm{~min}^{-1}$ data, the FO-DTS recorded warmest temperature areas on the right side of the mesocosm, while the TIR temperature data again indicated warmest temperatures on the left due to reflections from tree cover. The best calculated spatial correlation between FO-DTS and TIR temperature data occurred at 02:00 in the morning (Figure 2.b), whereby the FO-DTS and TIR data show a similar extent of warm water.

Under an injection rate of $15 \mathrm{~L} \mathrm{~min}^{-1}$, the worst spatial correlation between FO-DTS and TIR temperature data occurred at 13:00 in the afternoon (Figure 2.c), while the best correlation occurred at 20:00 (Figure 2.c). Unlike the lower injection rates, both cases showed a good degree of visual similarity between the FO-DTS and TIR temperature grids.

Taken together, these results indicate a reasonable degree of similarity between the FO-DTS and TIR data, particularly for the higher injection rates. The TIR signal corresponding to the warm water injection was also clearer at night-time than during the day.

$<$ Figure 2 here, please>

Figure 2. Visual comparison of TIR temperature data with FO-DTS temperature data. Worst (left) and best (right) spatially correlated datasets for overcast conditions at three pumping rates: a) $1 \mathrm{~L} \mathrm{~min}^{-1}$, b) $5 \mathrm{~L} \mathrm{~min}^{-1}$ and c) $15 \mathrm{~L} \mathrm{~min}^{-1}$. Temperature signal corresponding to the warm water injection is indicated with a black arrow in Figure 2.a and 2.b.

\section{Clear sky conditions}

Under clear sky conditions (Figure 3), simulated groundwater upwelling produced by the warm water injection was generally not detected by TIR. Figure 3 shows the FO-DTS and TIR temperature grids corresponding to the lowest and highest spatial correlations. The overall 
correlation between FO-DTS and TIR was systematically lower than under overcast skies, and no meaningful differences were observed between the computed worst and best spatial correlation values. Thus, there was little visual agreement between the TIR and FO-DTS data for any injection rate, throughout the entire diurnal cycle (see Figure 3.a and 3.b).

<Figure 3 here, please>

Figure 3. Visual ground truthing of TIR temperature data with FO-DTS temperature data. Worst (left) and best (right) correlated datasets for clear conditions at three pumping rates: a) $1 \mathrm{~L} \mathrm{~min}^{-1}$ and b) $5 \mathrm{~L} \mathrm{~min}^{-1}$.

\subsubsection{Quantitative comparison}

We calculated Global Moran's I coefficients between FO-DTS and TIR temperature data under overcast (Figure 4) and clear conditions (Figure 5) across the entire 24-hour long measurement cycle and for all simulated warm water injection rates (Figures 4 and 5: a) $1 \mathrm{~L} \mathrm{~min}^{-1}$ and b) $5 \mathrm{~L}$ $\min ^{-1}$ and Figure 4.c: $15 \mathrm{~L} \mathrm{~min}^{-1}$ ) with a view to ascertaining the time and conditions associated with the best and worst performance of the TIR methodology. Generally, we observed that Global Moran's I coefficient values under overcast conditions were higher than under clear conditions (see Figures 4 and 5), with the absolute highest values obtained for the $15 \mathrm{~L} \mathrm{~min}^{-1}$ injection rate (see Figure 4.c). Furthermore, for $1 \mathrm{~L} \mathrm{~min}^{-1}$ and $5 \mathrm{~L} \mathrm{~min}^{-1}$ injection rates under overcast conditions, the highest Global Moran's I coefficient values were obtained during night (see Figure 4.a and 4.b). 
Under clear conditions, Global Moran's I coefficient values (both $1 \mathrm{~L} \mathrm{~min}^{-1}$ and $5 \mathrm{~L} \mathrm{~min}^{-1}$ ) were generally lower than those observed under overcast weather conditions, and were often close to 0 or negative (see Figure 5.a and 5.b).

$<$ Figure 4 here, please $>$

Figure 4. Bivariate Global Moran's I values for spatial correlation between FO-DTS and TIR temperature data under overcast weather conditions, for three pumping rates: a) $1 \mathrm{~L} \mathrm{~min}^{-1}$, b) $5 \mathrm{~L}$ $\min ^{-1}$ and c) $15 \mathrm{~L} \mathrm{~min}^{-1}$.

$<$ Figure 5 here, please >

Figure 5. Bivariate Global Moran's I values for spatial correlation between FO-DTS and TIR temperature data under clear sky conditions, for two pumping rates: a) $1 \mathrm{~L} \mathrm{~min}^{-1}$ and b) $5 \mathrm{~L} \mathrm{~min}^{-}$ 1.

\section{Discussion}

\subsection{Comparison of TIR temperature data with FO-DTS temperature data}

Visual and quantitative comparison of the TIR temperatures with FO-DTS data demonstrated that best matches occurred during overcast weather conditions than during clear sky conditions, during night than during day and at higher injection rates than at lower injection rates (Figures 25). FO-DTS observations provided a spatially-explicit validation for the patterns observed in the TIR images for a range of different discharge rates, weather conditions and points along the diurnal cycle. The FO-DTS setup allowed for the differentiation of thermal anomalies related to 
groundwater upwelling from thermal anomalies present within the TIR images which were related to other factors (eg. reflections from vegetation). The use of near-surface mounted FODTS to validate TIR in this manner is novel, as the majority of other studies incorporating FODTS measurements and TIR use FO-DTS installed at the sediment-water interface (e.g. Lewandowski et al., 2013). In such studies, comparison of TIR images with FO-DTS temperature data is problematic because: a) depth-dependent mixing may fundamentally alter the thermal patterns received by the FO-DTS in comparison with TIR and b) the warming effect of incident radiation at the air water interface (eg. Benyahya et al., 2012; Marruedo Arricibita et al., 2018; Ouellet et al., 2014) may not be recorded by the bed-mounted FO-DTS. Our experimental setup provides a partial resolution of this problem, allowing for more direct comparison of the two techniques.

\subsection{Influence of discharge rates, weather conditions and the diurnal cycle}

\subsubsection{Simulated discharge rates}

Higher simulated discharge rates increased the ability of TIR to detect warm upwelling at the surface. The simulated discharge rates in the present study ( 1 to $15 \mathrm{~L} \mathrm{~min}^{-1}$ ) are at the higher end of LGD rates reported worldwide (eg. $745 \mathrm{~cm} \mathrm{day}^{-1}=5.2 \mathrm{~L} \mathrm{~m}^{-2} \mathrm{~min}^{-1}$ reported in Rosenberry et al., 2015). Examples of similarly high discrete LGD are found in Karst aquifers or in humic lakes with macropore groundwater discharge, occasionally exceeding $15 \mathrm{~L} \mathrm{~min}^{-1}$ (eg. Norrström and Jacks, 1996). Nevertheless, we appreciate that the simulated discharge rates are much higher than those typically observed in nature. Our values were chosen with a view to understanding the upper and lower limits of detectability using TIR in high discrete LGD environments under a best-case scenario. Thus, we do not recommend the extrapolation of our results or the use of TIR 
for studying LGD at the lower end of rates reported in the literature (eg. 0.005 to $124.1 \mathrm{~cm} \mathrm{day}^{-1}$; Rosenberry et al., 2015).

\subsubsection{Influence of weather conditions}

The present study builds on the mechanistic findings of Marruedo Arricibita et al. (2018) whereby the propagation of relatively warm water from the sediment to the air-water interface was tracked by several layers of FO-DTS cable in the water column. Marruedo Arricibita et al. (2018) showed that the propagation of relatively warm water heat signal from the sediment to the air-water interface was mainly influenced by the diurnal cycle of net radiation $(R n)$ and cloud cover, due to the role of $R n$ in controlling heat gains and losses at the water surface. These findings also have implications for the TIR results. During daytime, $R n$ values were higher under clear skies than under overcast weather conditions, due to increased incident shortwave radiation. This means that the water surface heated up more than under overcast weather conditions, rendering the signal from the warm water injection (at the base of the mesocosm) difficult to observe with TIR (because of the very small resultant temperature difference between the simulated upwelling and the ambient mesocosm surface temperature). On the contrary, during night-time, a greater amount of net radiation $(R n)$ was lost during clear sky conditions than under overcast conditions (Marruedo Arricibita et al., 2018). While this increased heat loss explains why the FO-DTS data was not able to properly characterise upwelling (due to rapid dissipation

of heat energy at the surface), it does not explain why the TIR images were not readily able to detect the upwelling, as it is this very loss of radiation which is measured by the thermal camera. Instead, we hypothesise that the formation of a (shallow) inverted thermocline resulting from the 
high surface energy loss may prevented warm water from reaching the surface prior to mixing, possibly explaining the lack of an observable plume extent in the TIR images.

The TIR sensor measures longwave radiation that is emitted and reflected from the water surface. This means that thermal images obtained from TIR cameras contain information on both water surface temperature and reflections from surrounding vegetation (in this case, tree cover next to the mesocosm) or cloud cover (Anderson and Wilson, 1984; Handcock et al., 2012; Schott, 1994; Torgersen et al., 2001). In addition, the sensor in the TIR camera detects radiation emitted from the upper $0.1 \mathrm{~mm}$ of the water surface (Torgersen et al., 2001), whereas the FODTS measured true kinetic temperature at $2 \mathrm{~cm}$ below the water surface. As a consequence, FODTS temperature measurements, unlike the TIR data, were not affected by radiation emitted by surrounding vegetation or clouds.

Under clear sky conditions, the TIR imagery incorporated artefacts generated from longwave reflections of tree cover. These artefacts caused temperature variations at the water surface and made it extremely difficult to discriminate the extent of the thermal plume associated with the warm water injection. The match with the FO-DTS data (which were not influenced by vegetation reflections) was therefore poor. Conversely, under overcast weather conditions, it was possible to discriminate the extent of the thermal plume associated with the warm water injection in the TIR image. We provide two possible explanations for this phenomenon. First, during overcast conditions, the TIR imagery incorporated longwave reflections not only from vegetation, but also from cloud cover. As a consequence, most reflections from vegetation were masked by bulk reflections of clouds, which provided a relatively uniform background in the TIR image. The thermal plume from the warm water injection into the mesocosm was thus 
visible against the uniform background, providing an improved degree of similarity between the FO-DTS and TIR data. Second, the decrease in solar radiation under overcast conditions meant that resulting longwave emissions from trees were also diminished, reducing the magnitude of reflections from tree cover.

\subsubsection{Influence of the diurnal cycle}

Although overcast conditions aided detection of the warm water injection during both day and night, it was generally easier to detect the thermal plume during the night, when longwave reflections from trees beside the mesocosm were minimized. Longwave emissions from vegetation are lower at night because vegetation temperature is generally reduced in comparison to daylight conditions (owing to a lack of incident shortwave radiation at night). This resulted in substantially weaker longwave emissions from vegetation to the water surface, eliminating vegetation reflections in the TIR images and further aiding discrimination of the thermal plume.

\subsection{Experimental shortcomings and future improvements}

The present experiment was conducted in a semi-controlled environment (a mesocosm with simulated groundwater discharge) in order to decrease the number of external influences (e.g. turbulence from waves, vegetation in the water column) on the ability of TIR to detect the warm water injection. This experimental setup allowed us to better isolate and investigate the influence of weather conditions (clear vs overcast) and the diurnal cycle (day vs night), which might otherwise be obscured by other external phenomena. Our results could be applied or extrapolated to shallow lakes up to $1 \mathrm{~m}$ deep, or shallow littoral environments, provided wind velocities and mixing were sufficiently similar. However, we acknowledge: (i) that in natural environments, the 
ability of TIR to detect warm groundwater upwelling in winter is also influenced by a range of other factors and; (ii) the limited number of parameters (discharge rates, weather conditions and diurnal cycle) included in this study. This experiment is a first attempt to understand under which conditions ground-based TIR remote sensing is a suitable method to detect discrete LGD at the water surface of slow flowing freshwater bodies such as lakes, ponds or reservoirs, in winter. Therefore, we advocate further research that will build upon the lessons learned from the results and conclusions presented in this paper, through the use of more detailed experimental designs capable of examining a larger variation of parameters (e.g. surface water depth, angle of the TIR camera or the range of $\Delta \mathrm{T}$ between surface water and groundwater) or future measurements in natural conditions (conducted from the shores of lakes).

\subsection{Implications of results for TIR based monitoring of groundwater upwelling}

Our study emphasizes the importance of considering the influences of weather conditions (clear vs overcast) and the diurnal cycle (day vs night) on TIR-based detection of LGD in slow flowing freshwater. The emphasis on the relevance of weather conditions and the diurnal cycle is in agreement with other recent investigations which also highlighted similar findings (e.g. bedrock groundwater seepage detection; Mundy et al., 2017; TIR imaging of high altitude alpine environments; Aubry-Wake et al., 2015;). Indeed, in a study designed to assess the influence of air temperature and solar radiation on ground-based TIR measurements of groundwater seepage from bedrock, Mundy et al. (2017) specifically recommended that TIR temperature measurements should be carried out when solar radiation is not present (during night) and in stable weather conditions. This finding supports our results and highlights the importance of conducting monitoring: i) at night and; ii) under overcast weather conditions. Thus, while close- 
range TIR techniques can constitute an effective tool for monitoring groundwater upwelling, their efficacy depends upon a wide range of environmental factors. Care must therefore be taken when performing similar work to control for the factors detailed in this paper to ensure optimal monitoring results.

We also note that our TIR imagery required post-processing to account for the effects of vignetting. Vignetting results in a circular gradient of decreasing image brightness from the centre of the image to its edges (Gupta, 2018; Lelong et al., 2008). Although commonly associated with optical remote sensing (eg. Kordecki et al., 2016; Meng et al., 2015), vignetting is also known to impact TIR images in a similar fashion (eg. Hook et al., 2005; Meier et al., 2011) resulting in generally 'cooler' temperatures towards the edges of TIR images. This effect is particularly pronounced with wide angle lenses (Goldman, 2010; Kelcey and Lucieer, 2012), such as the $12.5 \mathrm{~mm}\left(65^{\circ} \times 51^{\circ}\right.$ field-of-view) model used in our study. While such vignetting is therefore unlikely to present challenges for airborne TIR which benefit from the ability to use narrower field-of-view (FOV) lenses due to increased sensor to object distances, the use of wide FOV lenses is often a necessity in ground-based TIR studies in order to acquire imagery of a given study area in its entirety. Future ground-based studies of discrete LGD should therefore be aware of the potential for temperature bias resulting from the use of wide-angle lenses; such studies may therefore require the application of similar post-processing methodologies to account for this.

\section{Conclusion}

The manifestation of warm water upwelling at the surface of a mesocosm was monitored using TIR and compared to FO-DTS temperature observations for a range of different injection rates. 
Results show that the diurnal cycle of incoming net radiation as well as weather conditions (clear versus overcast skies) had a substantial effect on the ability of TIR to accurately detect simulated warm water upwelling (in comparison to FO-DTS records). While simulated warm water discharges were generally well detected during overcast conditions and at night, TIR was less able to replicate FO-DTS observations during day and under clear sky conditions. These findings have important implications for the use of TIR imaging to detect discrete LGD at the water surface of slow flowing freshwater bodies in winter. 


\section{Acknowledgments and Data}

Funding: This work was supported by the European Union's Seventh Framework programme for research; technological development and demonstration [grant number 60715]: Ecohydrological Interfaces as Critical Hotspots for Transformations of Ecosystem Exchange Fluxes (INTERFACES).

The data supporting the conclusions can be obtained in the results section, figures and references. Special thanks to Franziska Pöschke, Karin Meinikmann, Hauke Dämpfling and Anne Mehrtens for their technical and moral support.

Finally, we would like to thank the two anonymous reviewers and the editor Tim R. McVicar for the detailed and helpful reviews provided.

\section{References}

Allan, R.G., Pereira, L., Raes, D., Smith, M., 1998. Crop evapotranspiration-Guidelines for computing crop water requirements-FAO Irrigation and drainage paper 56.

Anderson, D.M., Glibert, P.M., Burkholder, J.M., 2002. Harmful algal blooms and eutrophication: Nutrient sources, composition, and consequences. Estuaries 25, 704-726. doi:10.1007/BF02804901

Anderson, J.M., Wilson, S.B., 1984. Review Article.The physical basis of current infrared remote-sensing techniques and the interpretation of data from aerial surveys. Int. J. Remote Sens. 1-18. doi:10.1080/01431168408948786

Anselin, L., 1995. Local Indicators of Spatial Association-LISA. Geogr. Anal. 27, 93-115. doi:10.1111/j.1538-4632.1995.tb00338.x

Anselin, L., Syabri, I., Smirnov, O., 2002. Visualizing Multivariate Spatial Correlation with 
Dynamically Linked Windows, in: Anselin, L., Rey, S. (Eds.), New Tools for Spatial Data Analysis:Proceedings of the Specialist Meeting. Santa Barbara.

Aubry-Wake, C., Baraer, M., McKenzie, J.M., Mark, B.G., Wigmore, O., Hellström, R., Lautz, L., Somers, L., 2015. Measuring glacier surface temperatures with ground-based thermal infrared imaging. Geophys. Res. Lett. 42, 8489-8497. doi:10.1002/2015GL065321

Baker, B.H., Martinovic-Weigelt, D., Ferrey, M., Barber, L.B., Writer, J.H., Rosenberry, D.O., Kiesling, R.L., Lundy, J.R., Schoenfuss, H.L., 2014. Identifying non-point sources of endocrine active compounds and their biological impacts in freshwater lakes. Arch. Environ. Contam. Toxicol. 67, 374-388. doi:10.1007/s00244-014-0052-4

Benyahya, L., Caissie, D., Satish, M.G., El-jabi, N., 2012. Long-wave radiation and heat flux estimates within a small tributary in Catamaran Brook ( New Brunswick, Canada ) 484, 475-484. doi:10.1002/hyp.8141

Boulton, A.J., Findlay, S., Marmonier, P., Stanley, E.H., Boulton, A.J., Findlay, S., Marmonier, P., Stanley, E.H., Valett, H.M., 1998. The Functional Significance of the Hyporheic Zone in Streams and Rivers Maurice Valett Source : Annual Review of Ecology and Systematics, Vol . 29 ( 1998 ), pp . 59-81 Published by: Annual Reviews Stable URL: http://www.jstor.org/stable/221702 REFERENC 29, 59-81.

Brabrand, A., Koestler, A.G., Borgstrøm, R., 2002. Lake spawning of brown trout related to groundwater influx. J. Fish Biol. 60, 751-763. doi:10.1006/jfbi.2002.1901

Briggs, M.A., Hare, D.K., Boutt, D.F., Davenport, G., Lane, J.W., 2016. Thermal infrared video details multiscale groundwater discharge to surface water through macropores and peat pipes. Hydrol. Process. 30, 2510-2511. doi:10.1002/hyp.10722

Briggs, M.A., Voytek, E.B., Day-Lewis, F.D., Rosenberry, D.O., Lane, J.W., 2013. 
Understanding water column and streambed thermal refugia for endangered mussels in the Delaware River. Environ. Sci. Technol. 47, 11423-11431. doi:10.1021/es4018893

Burnett, W.C., Aggarwal, P.K., Aureli, A., Bokuniewicz, H., Cable, J.E., Charette, M.A., Kontar, E., Krupa, S., Kulkarni, K.M., Loveless, A., Moore, W.S., Oberdorfer, J.A., Oliveira, J., Ozyurt, N., Povinec, P., Privitera, A.M.G., Rajar, R., Ramessur, R.T., Scholten, J., Stieglitz, T., Taniguchi, M., Turner, J. V, 2006. Quantifying submarine groundwater discharge in the coastal zone via multiple methods. Sci. Total Environ. 367, 498-543. doi:10.1016/j.scitotenv.2006.05.009

Burnett, W.C., Bokuniewicz, H., Huettel, M., Moore, W.S., Taniguchi, M., 2003. Groundwater and pore water inputs to the coastal zone. Biogeochemistry $66,3-33$. doi:10.1023/B:BIOG.0000006066.21240.53

Danielescu, S., MacQuarrie, K.T.B., 2011. Nitrogen loadings to two small estuaries , Prince Edward Island, Canada : a 2-year investigation of precipitation, surface water and groundwater contributions. Hydrol. Process. 957, 945-957. doi:10.1002/hyp.7881

Danielescu, S., MacQuarrie, K.T.B., Faux, R.N., 2009. The integration of thermal infrared imaging, discharge measurements and numerical simulation to quantify the relative contributions of freshwater inflows to small estuaries in Atlantic Canada. Hydrol. Process. 23, 2847-2859. doi:10.1002/hyp.7383

Davies, A.G., Calkins, J., Scharenbroich, L., Vaughan, R.G., Wright, R., Kyle, P., Castańo, R., Chien, S., Tran, D., 2008. Multi-instrument remote and in situ observations of the Erebus Volcano (Antarctica) lava lake in 2005: A comparison with the Pele lava lake on the jovian moon Io. J. Volcanol. Geotherm. Res. 177, 705-724. doi:10.1016/j.jvolgeores.2008.02.010 Dugdale, S.J., 2016. A practitioner's guide to thermal infrared remote sensing of rivers and 
streams: recent advances, precautions and considerations. Wiley Interdiscip. Rev. Water 3, 251-268. doi:10.1002/wat2.1135

Dugdale, S.J., Bergeron, N.E., St-Hilaire, A., 2015. Spatial distribution of thermal refuges analysed in relation to riverscape hydromorphology using airborne thermal infrared imagery. Remote Sens. Environ. 160, 43-55. doi:10.1016/j.rse.2014.12.021

Frisbee, M.D., Shope, C.L., Briggs, M., Boutt, D.F., 2016. Field Methods for the Evaluation of Groundwater and Surface-Water Interactions, in: Cushman, J.H., Tartakovski, D.M. (Eds.), The Handbook of Groundwater Engineering. CRC Press.

Goldman, D.B., 2010. Vignette and exposure calibration and compensation. IEEE Trans. Pattern Anal. Mach. Intell. 32, 2276-2288. doi:10.1109/TPAMI.2010.55

Gupta, R.P., 2018. Image Quality and Principles of Interpretation, in: Remote Sensing Geology. Springer Berlin Heidelberg, Berlin, Heidelberg, pp. 107-114. doi:10.1007/978-3-66255876-8_9

Handcock, R.N., Torgersen, C.E., Cherkauer, K.A., Gillespie, A.R., Tockner, K., Faux, R.N., Tan, J., 2012. Thermal Infrared Remote Sensing of Water Temperature in Riverine Landscapes. Fluv. Remote Sens. Sci. Manag. 85-113. doi:10.1002/9781119940791.ch5

Hare, D.K., Briggs, M.A., Rosenberry, D.O., Boutt, D.F., Lane, J.W., 2015. A comparison of thermal infrared to fiber-optic distributed temperature sensing for evaluation of groundwater discharge to surface water. J. Hydrol. 530, 153-166. doi:10.1016/j.jhydrol.2015.09.059

Hayashi, M., Rosenberry, D.., 2002. Effects of Ground Water Exchange on the Hydrology and Ecology of Surface Water. Ground Water 40, 309-316.

Hook, S.J., Clodius, W.B., Balick, L., Alley, R.E., Abtahi, A., Richards, R.C., Schladow, S.G., 2005. In-flight validation of mid- and thermal infrared data from the Multispectral Thermal 
Imager (MTI) using an automated high-altitude validation site at Lake Tahoe CA/NV, USA. IEEE Trans. Geosci. Remote Sens. 43, 1991-1999. doi:10.1109/TGRS.2005.853191

Hu, C., Muller-karger, F.E., Swarzenski, P.W., 2006. Hurricanes , submarine groundwater discharge, and Florida's s red tides. Geophys. Res. Lett. 33, 1-5. doi:10.1029/2005GL025449

Johnson, A.G., Glenn, C.R., Burnett, W.C., Peterson, R.N., Lucey, P.G., 2008. Aerial infrared imaging reveals large nutrient-rich groundwater inputs to the ocean. Geophys. Res. Lett. 35, 1-6. doi:10.1029/2008GL034574

Kelcey, J., Lucieer, A., 2012. Sensor correction of a 6-band multispectral imaging sensor for UAV remote sensing. Remote Sens. 4, 1462-1493. doi:10.3390/rs4051462

Kordecki, A., Palus, H., Bal, A., 2016. Practical vignetting correction method for digital camera with measurement of surface luminance distribution. Signal, Image Video Process. 10, 1417-1424. doi:10.1007/s11760-016-0941-2

Krause, S., Blume, T., 2013. Impact of seasonal variability and monitoring mode on the adequacy of fiber-optic distributed temperature sensing at aquifer-river interfaces. Water Resour. Res. 49, 2408-2423. doi:10.1002/wrcr.20232

Lee, E., Kang, K., Hyun, S.P., Lee, K.-Y., Yoon, H., Kim, S.H., Kim, Y., Xu, Z., Kim, D., Koh, D.-C., Ha, K., 2016. Submarine groundwater discharge revealed by aerial thermal infrared imagery: a case study on Jeju Island, Korea. Hydrol. Process. 3506, 3494-3506.

doi:10.1002/hyp.10868

Lee, Y., Kim, G., 2007. Linking groundwater-borne nutrients and dinoflagellate red-tide outbreaks in the southern sea of Korea using a Ra tracer. Estuar. Coast. Shelf Sci. 71, 309317. doi:10.1016/j.ecss.2006.08.004 
Lega, M., Napoli, R.M. a., 2010. Aerial infrared thermography in the surface waters contamination monitoring. Desalin. Water Treat. 23, 141-151. doi:10.5004/dwt.2010.1988

Lelong, C.C.D., Burger, P., Jubelin, G., Roux, B., Labbé, S., Baret, F., 2008. Assessment of unmanned aerial vehicles imagery for quantitative monitoring of wheat crop in small plots. Sensors 8, 3557-3585. doi:10.3390/s8053557

Lewandowski, J., Meinikmann, K., Ruhtz, T., Pöschke, F., Kirillin, G., 2013. Localization of lacustrine groundwater discharge (LGD) by airborne measurement of thermal infrared radiation. Remote Sens. Environ. 138, 119-125. doi:10.1016/j.rse.2013.07.005

Marruedo Arricibita, A.I., Krause, S., Gomez-Velez, J., Hannah, D.M., Lewandowski, J., 2018. Mesocosm experiments identifying hotspots of groundwater upwelling in a water column by fibre optic distributed temperature sensing. Hydrol. Process. 32, 185-199. doi:10.1002/hyp.11403

Meier, F., Scherer, D., Richters, J., Christen, A., 2011. Atmospheric correction of thermalinfrared imagery of the 3-D urban environment acquired in oblique viewing geometry. Atmos. Meas. Tech. 4, 909-922. doi:10.5194/amt-4-909-2011

Meinikmann, K., Lewandowski, J., Nützmann, G., 2013. Lacustrine groundwater discharge: Combined determination of volumes and spatial patterns. J. Hydrol. 502, 202-211. doi:10.1016/j.jhydrol.2013.08.021

Meng, H., Guan, W., Liu, C., Wu, Q., 2015. Algorithm research of vignetting distortion correction based on near-infrared CCD thermometer, in: Design, Manufacturing and Mechatronics. WORLD SCIENTIFIC, pp. 1290-1298. doi:10.1142/9789814730518_0151 Mundy, E., Gleeson, T., Roberts, M., Baraer, M., Mckenzie, J.M., 2017. Thermal Imagery of Groundwater Seeps: Possibilities and Limitations. Groundwater. doi:10.1111/gwat.12451 
Nakayama, T., Watanabe, M., 2008. Missing role of groundwater in water and nutrient cycles in the shallow eutrophic Lake Kasumigaura, Japan. Hydrol. Process. 22, 1150-1172. doi:10.1002/hyp.6684

Neale, C.M.U., Jaworowski, C., Heasler, H., Sivarajan, S., Masih, A., 2016. Hydrothermal monitoring in Yellowstone National Park using airborne thermal infrared remote sensing. Remote Sens. Environ. 184, 628-644. doi:10.1016/j.rse.2016.04.016

Norrström, A.C., Jacks, G., 1996. Water pathways and chemistry at the groundwater/surface water interface to Lake Skjervatjern, Norway. Water Resour. Res. 32, 2221-2229. doi:0043-1397/96/96WR-00802

Ouellet, V., Secretan, Y., St-Hilaire, A., Morin, J., 2014. Water temperature modelling in a controlled environment: Comparative study of heat budget equations. Hydrol. Process. 28, 279-292. doi:10.1002/hyp.9571

Röper, T., Greskowiak, J., Massmann, G., 2014. Detecting Small Groundwater Discharge Springs Using Handheld Thermal Infrared Imagery. Groundwater 52, 936-942. doi:10.1111/gwat.12145

Rosenberry, D.O., Briggs, M.A., Voytek, E.B., Lane, J.W., 2016. Influence of groundwater on distribution of dwarf wedgemussels (Alasmidonta heterodon) in the upper reaches of the Delaware River, northeastern USA. Hydrol. Earth Syst. Sci. 20, 4323-4339. doi:10.5194/hess-20-4323-2016

Rosenberry, D.O., Lewandowski, J., Meinikmann, K., N??tzmann, G., 2015. Groundwater - the disregarded component in lake water and nutrient budgets. Part 1: Effects of groundwater on hydrology. Hydrol. Process. 29, 2895-2921. doi:10.1002/hyp.10403

Schott, J.R., 1994. Thermal Infrared Calibration of Aerial and Satellite Images Over Land, in: 
Geoscience and Remote Sensing Symposium. IEEE, Pasadena, CA, pp. 1-4. doi:10.1109/IGARSS.1994.399083

Schuetz, T., Weiler, M., 2011. Quantification of localized groundwater inflow into streams using ground-based infrared thermography. Geophys. Res. Lett. 38, 1-5. doi:10.1029/2010GL046198

Schuetz, T., Weiler, M., Lange, J., Stoelzle, M., 2012. Two-dimensional assessment of solute transport in shallow waters with thermal imaging and heated water. Adv. Water Resour. 43, 67-75. doi:10.1016/j.advwatres.2012.03.013

Shaw, R.D., Shaw, J.F.H., Fricker, H., Prepas, E.E., 1990. An integrated approach to quantify groundwater transport of phosphorus to Narrow Lake, Alberta 35, 870-886.

Sobrino, J.A., Del Frate, F., Drusch, M., Jiménez-Muñoz, J.C., Manunta, P., Regan, A., 2016. Review of thermal infrared applications and requirements for future high-resolution sensors. IEEE Trans. Geosci. Remote Sens. 54, 2963-2972. doi:10.1109/TGRS.2015.2509179

Tamborski, J.J., Rogers, A.D., Bokuniewicz, H.J., Cochran, J.K., Young, C.R., 2015. Identification and quantification of diffuse fresh submarine groundwater discharge via airborne thermal infrared remote sensing. Remote Sens. Environ. 171, 202-217. doi:10.1016/j.rse.2015.10.010

Taniguchi, M., Burnett, W.C., Cable, J.E., Turner, J. V, 2002. Investigation of submarine groundwater discharge. Hydrol. Process. 2129, 2115-2129. doi:10.1002/hyp.1145

Tcherepanov, E.N., Zlotnik, V. a., Henebry, G.M., 2005. Using Landsat thermal imagery and GIS for identification of groundwater discharge into shallow groundwater-dominated lakes. Int. J. Remote Sens. 26, 3649-3661. doi:10.1080/01431160500177315

Tempelhahn, A., Budzier, H., Krause, V., Gerlach, G., 2016. Shutter-less calibration of uncooled 
infrared cameras. J. Sensors Sens. Syst. 5, 9-16. doi:10.5194/jsss-5-9-2016

Tempelhahn, A., Budzier, H., Krause, V., Gerlach, G., 2015. Development of a shutterless calibration process for microbolometer-based infrared measurement systems. e-journal Nonde- structive Test. 20. doi:10.21611/qirt.2014.060

Torgersen, C.E., Faux, R.N., McIntosh, B.A., Poage, N.J., Norton, D.J., 2001. Airborne thermal remote sensing for water temperature assessment in rivers and streams. Remote Sens. Environ. 76, 386-398. doi:10.1016/S0034-4257(01)00186-9

Wang, X., Wang, X., Fan, J., Wen, S., Zhao, J., Su, X., 2016. Comparison of different spatial resolution thermal infrared data in monitoring thermal plume from the Hongyanhe nuclear power plant. 2016 IEEE Int. Geosci. Remote Sens. Symp. 4649-4652. doi:10.1109/IGARSS.2016.7730213

Warren, D.R., Sebestyen, S.D., Josephson, D.C., Lepak, J.M., Kraft, C.E., 2005. Acidic Groundwater Discharge and in Situ Egg Survival in Redds of Lake-Spawning Brook Trout. Trans. Am. Fish. Soc. 134,1193-1201. doi:10.1577/T04-180.1

Wawrzyniak, V., Piégay, H., Allemand, P., Vaudor, L., Goma, R., Grandjean, P., 2016. Effects of geomorphology and groundwater level on the spatio-temporal variability of riverine cold water patches assessed using thermal infrared (TIR) remote sensing. Remote Sens. Environ. 175, 337-348. doi:10.1016/j.rse.2015.12.050

Wirth, L., Rosenberger, A., Prakash, A., Gens, R., Margraf, J.F., Hamazak, T., 2012. A remotesensing, gis-based approach to identify, characterize, and model spawning habitat for fallrun chum salmon in a sub-arctic, glacially fed River. Trans. Am. Fish. Soc. 141, 13491363. doi: $10.1080 / 00028487.2012 .692348$ 


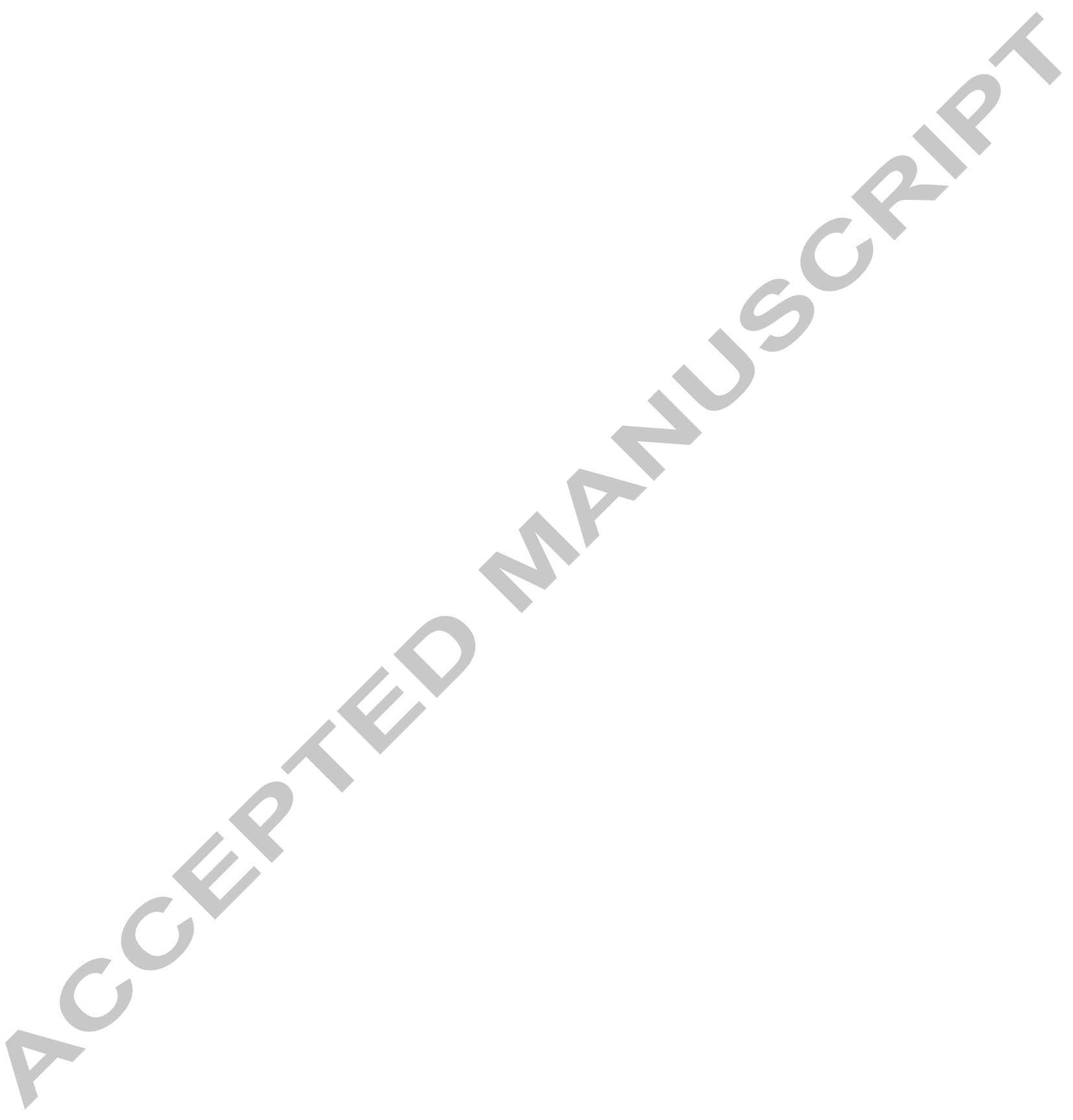




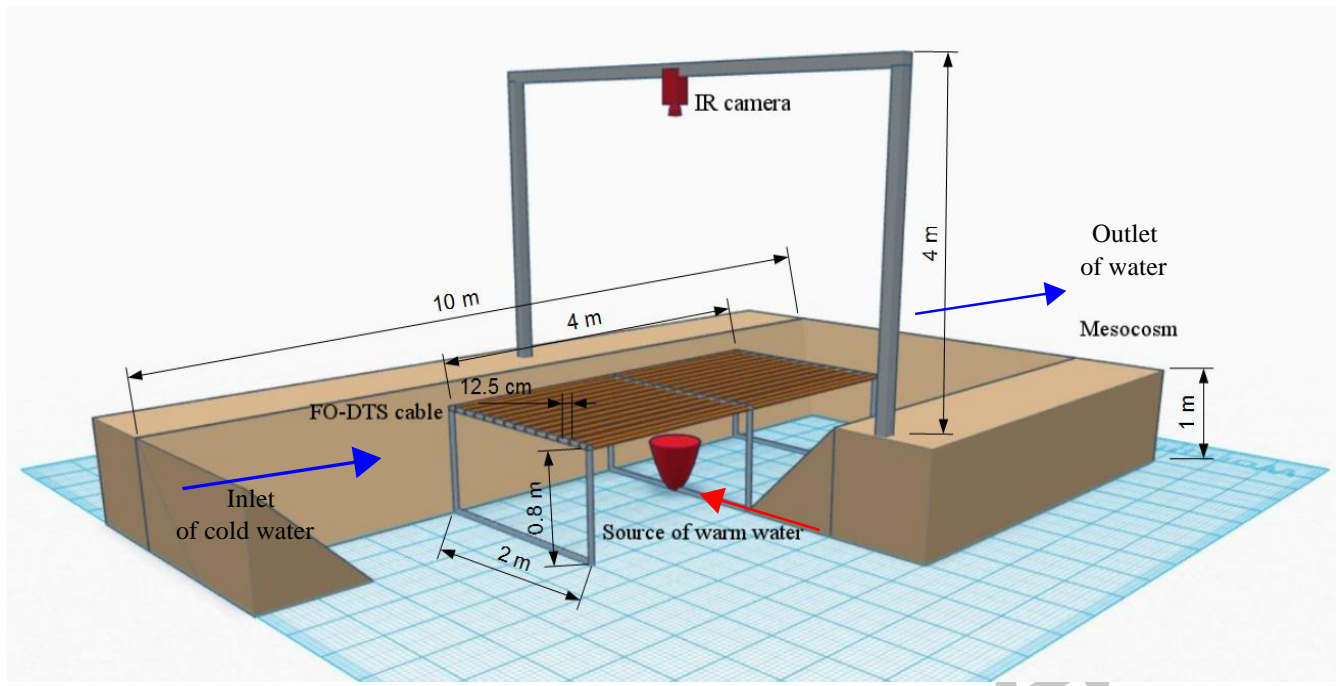

Figure 1. Schematic of the mesocosm experimental design including TIR setup and the upper layer of the FO-DTS. 


\section{OVERCAST}

a)

b)

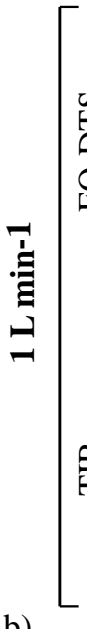

WORST

26. March 20:00
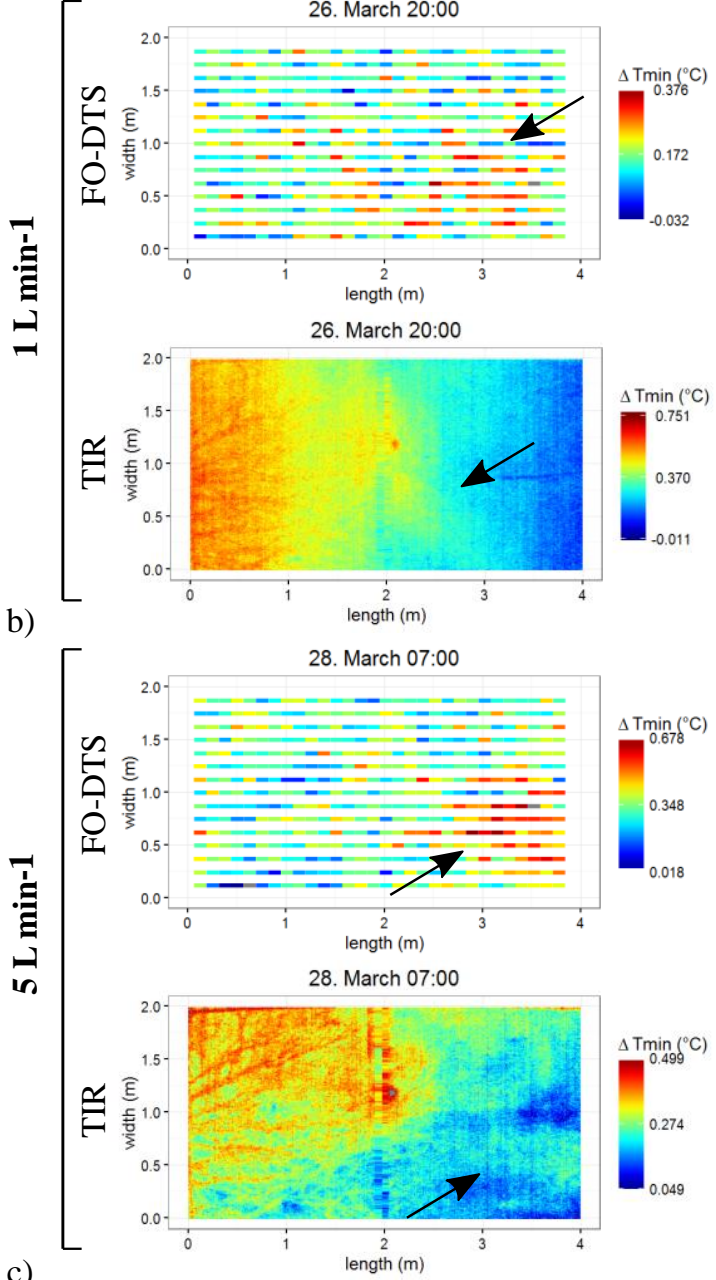

c)

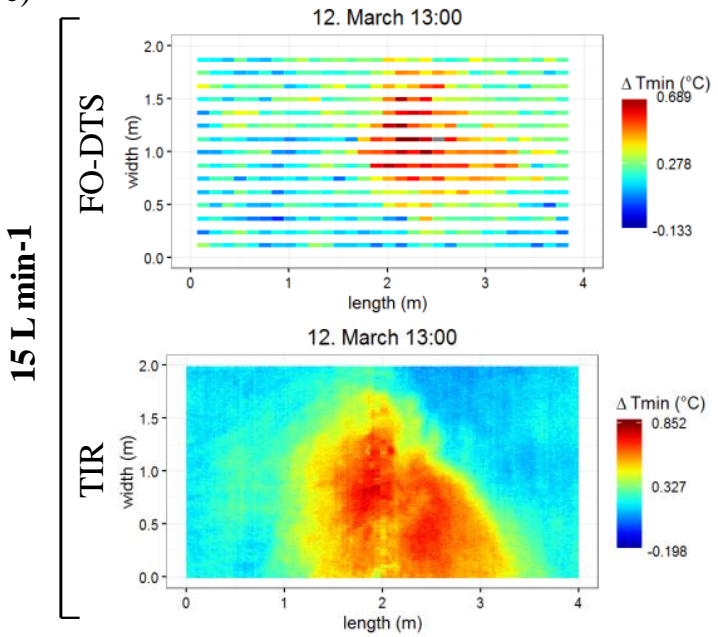

BEST
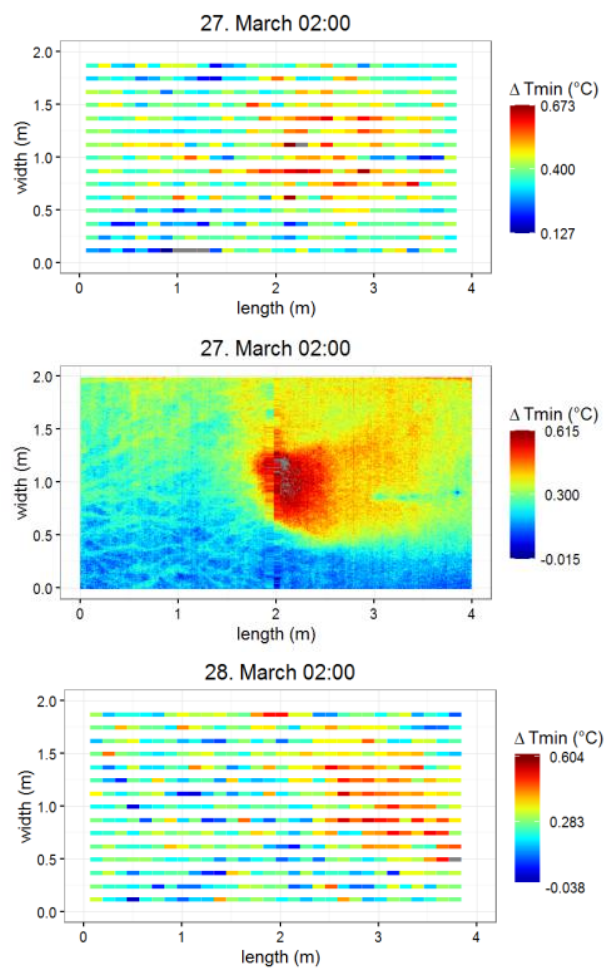

28. March 02:00

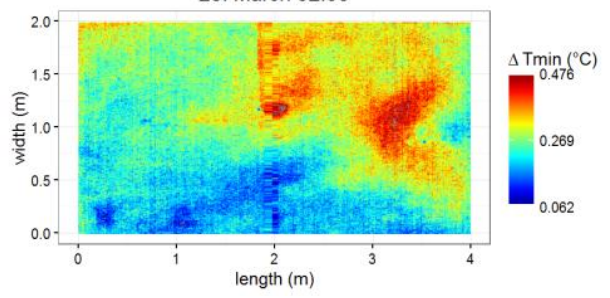

12. March $20: 00$

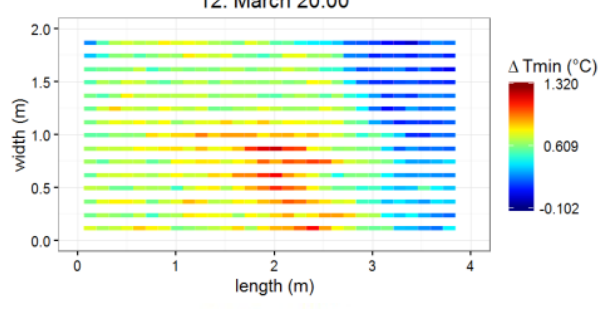

12. March 20:00

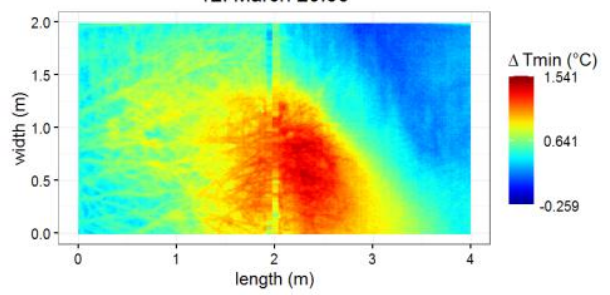

Figure 2. Visual comparison of TIR temperature data with FO-DTS temperature data. Worst (left) and best (right) spatially correlated datasets for overcast conditions at three pumping rates: 
a) $1 \mathrm{~L} \mathrm{~min}^{-1}$, b) $5 \mathrm{~L} \mathrm{~min}^{-1}$ and c) $15 \mathrm{~L} \mathrm{~min}^{-1}$. Temperature signal corresponding to the warm water injection is indicated with a black arrow in Figure 2.a and 2.b.

\section{CLEAR}
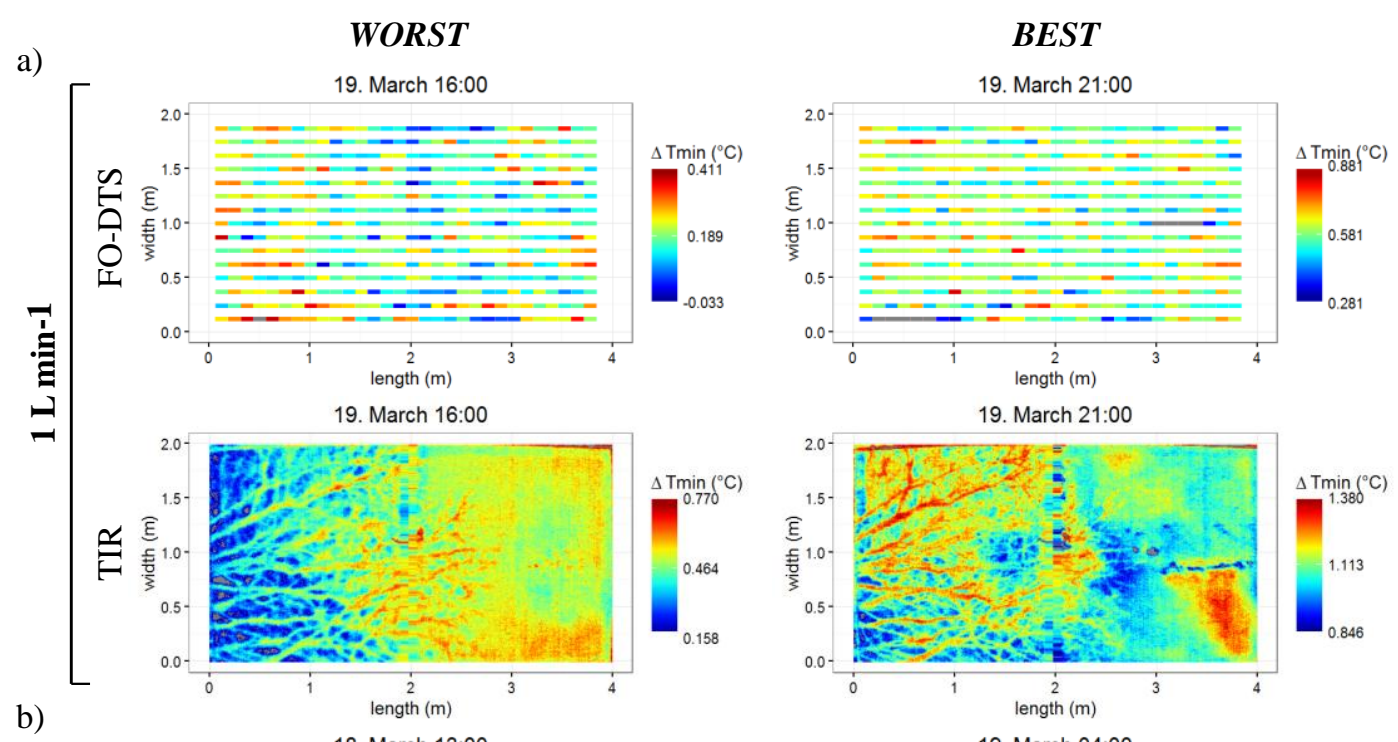

b)

18. March 13:00
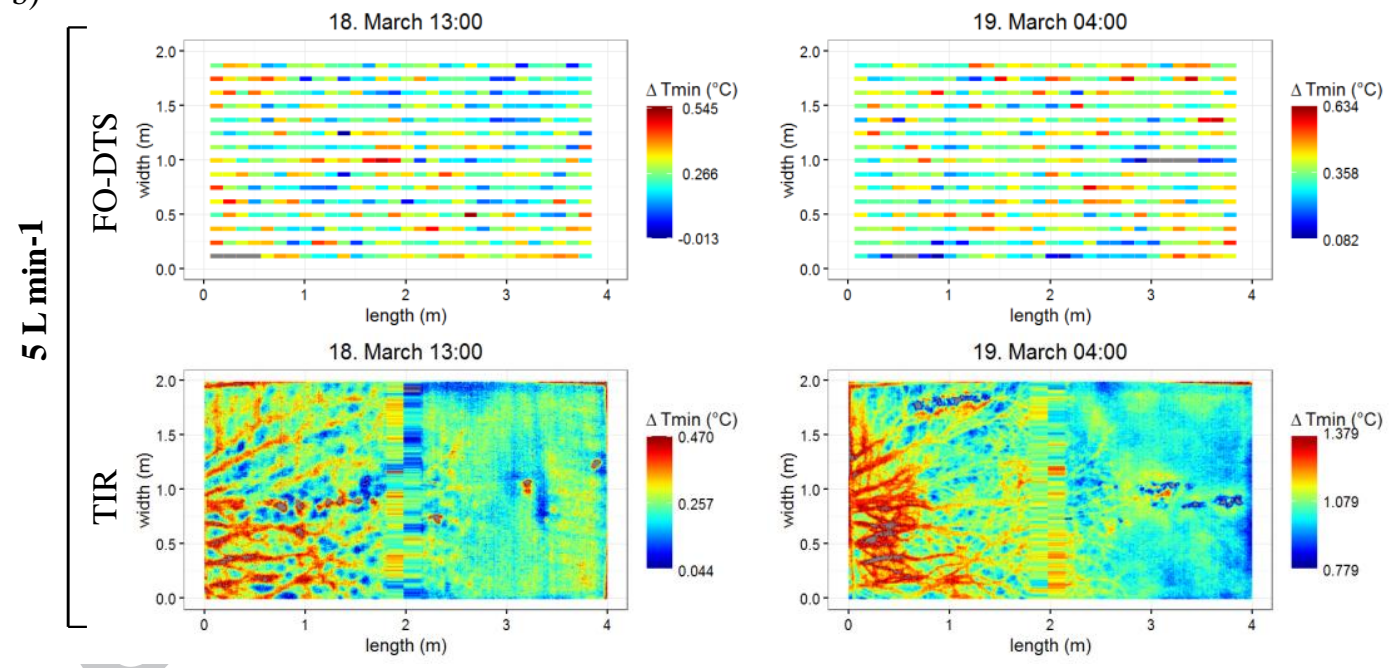

Figure 3. Visual comparison of TIR temperature data with FO-DTS temperature data. Worst (left) and best (right) correlated datasets for clear conditions at three pumping rates: a) $1 \mathrm{~L} \mathrm{~min}^{-1}$ and b) $5 \mathrm{~L} \mathrm{~min}^{-1}$. 

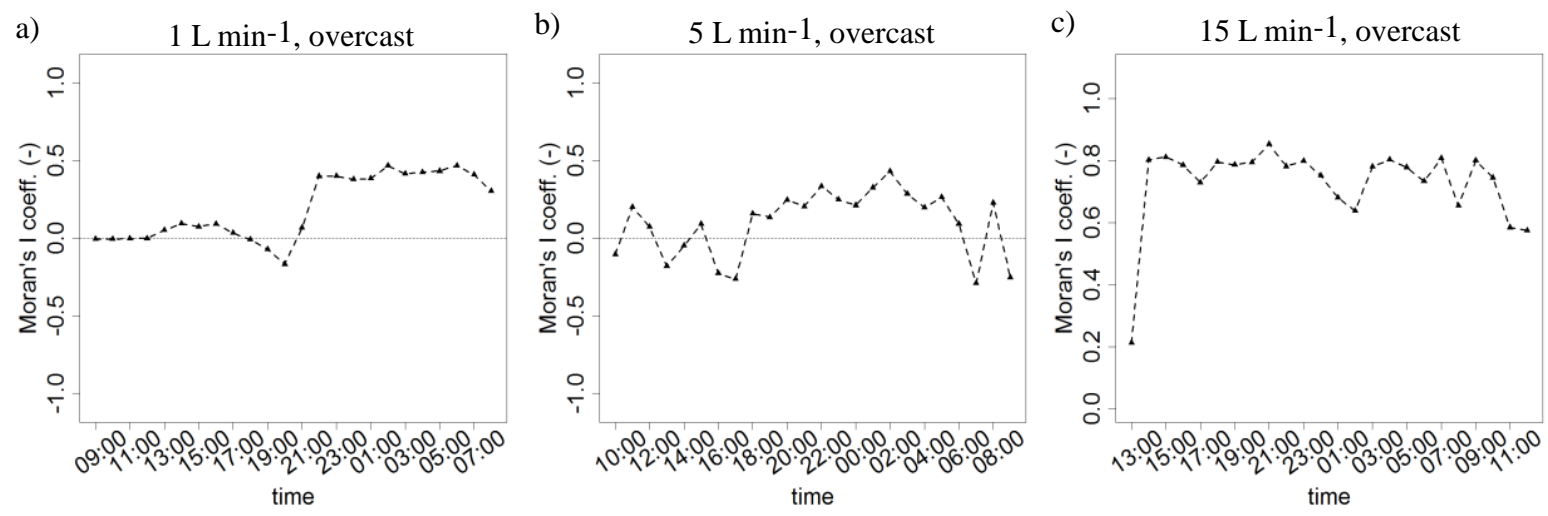

Figure 4. Bivariate Global Moran's I values for spatial correlation between FO-DTS and TIR temperature data under overcast weather conditions, for three pumping rates: a) $1 \mathrm{~L} \mathrm{~min}^{-1}$, b) $5 \mathrm{~L}$ $\min ^{-1}$ and c) $15 \mathrm{~L} \mathrm{~min}^{-1}$.
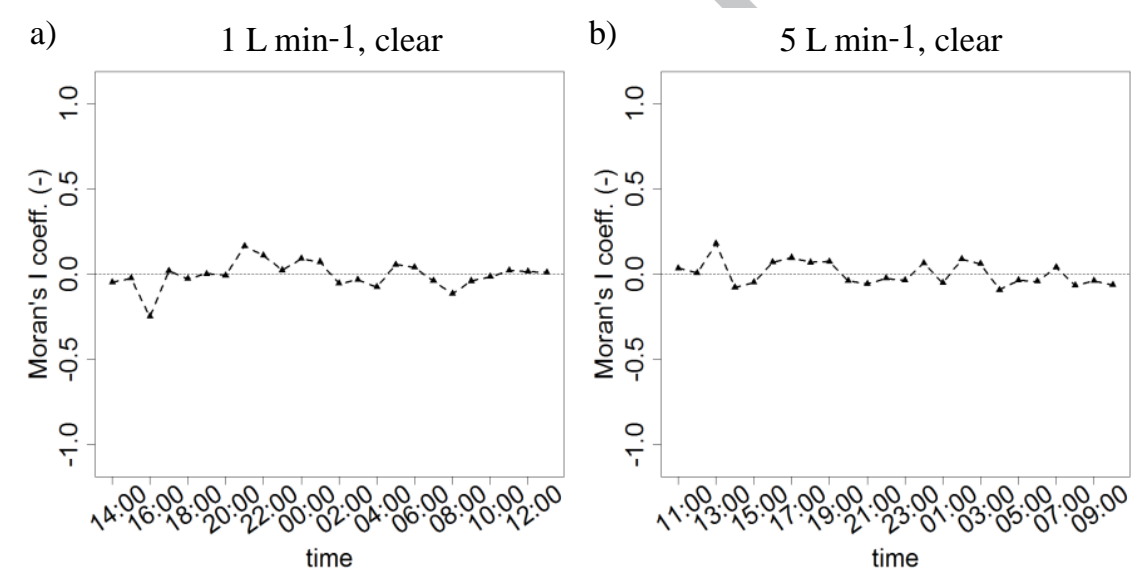

Figure 5. Bivariate Global Moran's I values for spatial correlation between FO-DTS and TIR temperature data under clear sky conditions, for two pumping rates: a) $1 \mathrm{~L} \mathrm{~min}^{-1}$ and b) $5 \mathrm{~L} \mathrm{~min}^{-}$ 
Table 1. 24-hour measurements with FO-DTS and TIR camera. The control dataset is only used as a reference for the initial conditions of the mesocosm measurements and is not included in the results.

\begin{tabular}{lll}
\hline Injection rate $\left(\mathbf{L ~} \mathbf{~ m i n}^{-\mathbf{1}}\right)$ & Weather conditions & Date (in March 2015) \\
\hline $\mathbf{0}$ (control) & overcast & 11 \\
$\mathbf{1}$ & clear & 19 \\
$\mathbf{1}$ & overcast & 26 \\
$\mathbf{5}$ & clear & 18 \\
$\mathbf{5}$ & overcast & 27 \\
$\mathbf{1 5}$ & overcast & 12 \\
\hline
\end{tabular}


Thermal infrared imaging for the detection of relatively warm lacustrine groundwater discharge at the surface of freshwater bodies

\section{Highlights}

- Distributed Temperature Sensing (DTS) $2 \mathrm{~cm}$ below the water surface validated TIR data.

- TIR best detected Lacustrine Groundwater Discharge (LGD) under overcast conditions and at night.

- Large LGD rates that occur only in exceptional cases are required for reliable detection by TIR. 